\title{
Application of Taguchi approach on investigation of formability for perforated Al 8011 sheets
}

\author{
K. Elangovan ${ }^{1}$, C. Sathiya Narayanan ${ }^{1}$ \\ ${ }^{I}$ Department of Production Engineering, National Institute of Technology, Tiruchirappalli, INDIA \\ "Corresponding Author: e-mail:elangs77@yahoo.co.in, Tel +91-9942134674, Fax.+91-431-2500133
}

\begin{abstract}
Sheet metal forming is a vital manufacturing process used in the automobile, aerospace, agriculture and architecture industries. The sheet metal is formed to various shapes to make useful components. The perforated sheets replace the solid sheet in some applications because of aesthetic appearance and low weight compared to solid sheet metal. The ability of the sheet metals to be formed into various shapes without failure is termed as formability. The formability of perforated sheet depends on chemistry of the material, the forming parameters, dimensions of the perforations and ligament width. In this paper, the forming limit diagram for perforated $\mathrm{Al} 8011$ sheet of $1 \mathrm{~mm}$ thickness has been evaluated and the influences of the diameters of perforations and ligament widths on the forming limit strains have been studied. The ligament width is the most influencing factor which has the percentage contribution of 70.04 and 72.55 in Tension-Compression, 69.65 in Plane strain and 51.49 and 71.84 in Tension-Tension conditions. This work gives reasonable forming limit plastic strains of the perforated sheets with various combinations of the diameters of perforations and ligament widths and also gives the prediction of these strains by varying it.
\end{abstract}

Keywords: Forming limit diagram, Perforated Al 8011, Limiting strain, Taguchi, Analysis of variance.

\section{Introduction}

1.1 Forming of perforated sheets: In sheet metal forming process, a sheet metal blank is plastically deformed under the action of punch and die to obtain the preferred final shape. It plays a significant role in automobile, aerospace, agriculture and architecture industries. The requirements associated with personalized production and cost reduction are the two major causes for improvement in sheet metal forming processes. The concept of a forming limit diagram (FLD) was developed by Keeler (1965) and Goodwin (1968) to study the formability of sheet metals. The FLD, which has consequently been widely referenced in the sheet metal forming industry, it is now a standard characteristic in the optimization of sheet metal forming processes. The perforated sheets are produced from the solid sheet by punching process. The main purposes of making perforations are to reduce the weight of the component made by sheet metal and to provide aesthetic appearance. Being the chemistry of the sheet metal and forming parameters constant, the formability of the perforated sheets mainly depends on the size of the perforation and ligament width. The perforated aluminium sheets are used in variety of applications including automotive, acoustics, architecture, interior design, displays, manufacturing, safety flooring, agriculture, pollution control, transportation, and mining etc (http://www.perforatedsheet.net/perforatedsheet/uses.html). A number of theoretical treatments have been developed to study the plastic behavior of perforated sheets (Chen, 1993; Baik et al., 1995; Baik et al., 1997; Baik et al., 1997; Lee and Chen, 2000). Conversely, there are very few reports on the experimental studies on formability of perforated sheets. In this paper, an approach based on the Taguchi method has been used to determine the influence of size of perforation and ligament width on the limiting major strain and limiting minor strain during forming of perforated aluminium 8011 sheet.

1.2 Taguchi techniques and analysis of variance: Taguchi method is a powerful methodology/ technique for the design of high quality systems (Taguchi, 1990). Taguchi technique has been widely used in engineering design (Ross, 1988). Taguchi design provides a simple, efficient and systematic approach to optimize design for performance, quality and cost over a verity of 
conditions. Taguchi's approach to design of experiment is easy to adopt and apply for users with limited knowledge of statistics hence it has gained a wide popularity in the engineering and scientific community (Montgomery, 1997). It consist of a plan of experiments with the objective of acquiring data in a controlled way, executing these experiments, in order to obtain information about the behavior of a given system. After the completion of the experiment the data from all the experiments in the set are analyzed to determine the effect of the various design parameters. Conducting Taguchi experiments in terms of orthogonal array allows the effects of several parameters efficiently. The treatment of experimental results is based on the analysis of variance (ANOVA) (Ross, 1988; Taguchi and Konishi, 1987; Taguchi, 1993; Ko et al., 1999; Li et al., 2006). Mahapatra and Chaturvedi (2009) made an attempt has been made to study the abrasive behaviour of untreated sugarcane fibre reinforced composites in a simplified manner and develop empirical model. The effect of various test parameters and their interactions have been studied using Taguchi method to find out optimal parameter setting for minimum wear (weight loss). It has been observed that fibre length plays a major role in wear phenomenon. Moshat et al. (2010) adapted Taguchi method to optimize CNC end milling process parameters to provide good surface finish as well as high material removal rate (MRR). The surface finish and material removal rate have been identified as quality attributes and are assumed to be directly related to productivity. Moshat et al. (2010) presented optimization technique of $\mathrm{CNC}$ end milling process parameters to provide good surface finish and high material removal rate (MRR). The surface finish of the machined surface has been identified as quality attribute whereas MRR has been treated as performance index directly related to productivity. Mathivanan et al. (2010) presented a simple and efficient way to study the influence of injection molding variables on sink marks using Taguchi approach.

The experimental investigation and statistical analysis on formability of perforated sheet metal is not carried by the researchers. Hence, the main objective of this research work is to investigate the forming limit strains of perforated Al 8011 alloy sheets experimentally and the influences of the input parameter (diameter of perforation and ligament width) on forming limit strains through statistical analysis.

\section{Experimental Procedure}

2.1 Specimen preparation: Aluminium sheets are extensively used in automobile industries next to steel (Mary-Anne Kulas et al., 2007) due to its light weight and good resistance to corrosion. Among the Aluminium alloys of various grades, Al 8011 possesses good strength. Due to this reason, Al 8011 sheets has been chosen for this study. Perforations to the desired dimensions were made by punching processes in the required pattern. In this study straight pattern is chosen, shown in Fig. 1. The circular perforations with $3 \mathrm{~mm}, 4 \mathrm{~mm}$ and $5 \mathrm{~mm}$ diameters and the ligament widths of $5 \mathrm{~mm}, 7.5 \mathrm{~mm}$ and $10 \mathrm{~mm}$ were chosen for this study due to the reason that these diameters and ligament widths are commonly used in industries. As in a standard FLD test (Narayanasamy et al., 2008), blanks of dimensions 300X200, 300X180, 300X160, 300X140, 300X120, 300X120, 300X100 and 300X80mm were sheared from these perforated sheets. With various combinations of diameters of perforations and ligament widths, nine sets of FLD samples were prepared. The thickness of the sheet chosen for this study is $1 \mathrm{~mm}$. the chemical composition of Al 8011 alloy taken for this study is given in Table 1.

Table 1. The chemical composition of Al $8011(\% \mathrm{~W})$

\begin{tabular}{|c|c|c|c|c|c|c|}
\hline Al & Fe & Si & Mn & Zn & Cr & Mg \\
\hline Reminder & 1.290 & 0.603 & 0.024 & 0.153 & 0.014 & 0.075 \\
\hline
\end{tabular}

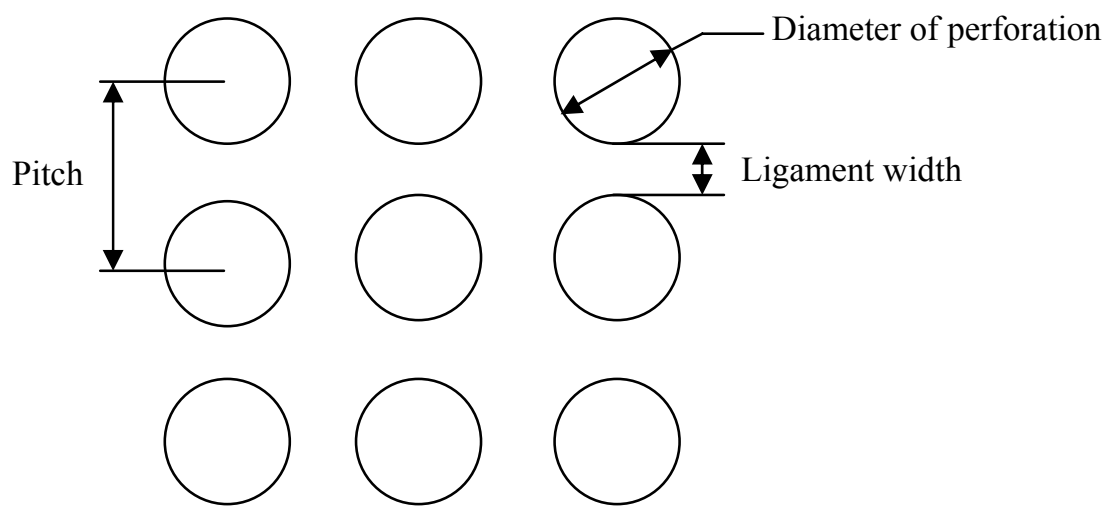

Figure 1. Straight pattern of perforations 
2.2 Design of experiment: The experimental design was done according to an $\mathrm{L}_{9}$ orthogonal array based on the Taguchi method. The use of Taguchi orthogonal array would evidently reduce the number of experiments. The $\mathrm{L}_{9}$ orthogonal array had four columns and nine rows, so it had eight degrees of freedom to manipulate four parameters with three levels as indicated in Table 2. Thus, four parameters can be assigned to the columns and the rows designate nine experiments with various combination levels of the parameters. In this investigation only two parameters with three levels were considered and indicated in Table 3 . The other two columns assigned for interaction.

Table 2. Orthogonal array $\mathrm{L}_{9}\left(3^{4}\right)$ of Taguchi

\begin{tabular}{|c|c|c|c|c|}
\hline $\mathbf{L}_{\mathbf{9}} \mathbf{( 3}^{\mathbf{4}} \mathbf{)}$ Test & $\mathbf{1}$ & $\mathbf{2}$ & $\mathbf{3}$ & $\mathbf{4}$ \\
\hline 1 & 1 & 1 & 1 & 1 \\
\hline 2 & 1 & 2 & 2 & 2 \\
\hline 3 & 1 & 3 & 3 & 3 \\
\hline 4 & 2 & 1 & 2 & 3 \\
\hline 5 & 2 & 2 & 3 & 1 \\
\hline 6 & 2 & 3 & 1 & 2 \\
\hline 7 & 3 & 1 & 3 & 3 \\
\hline 8 & 3 & 2 & 1 & 1 \\
\hline 9 & 3 & 3 & 2 & \\
\hline
\end{tabular}

Table 4. Assignment of the levels to the factors

\begin{tabular}{|c|c|c|}
\hline Level & Diameter of the perforation D $(\mathrm{mm})$ & Ligament width $\mathrm{W}(\mathrm{mm})$ \\
\hline 1 & 3 & 5 \\
\hline 2 & 4 & 7.5 \\
\hline 3 & 5 & 10 \\
\hline
\end{tabular}

2.3 Forming limit diagram: The prepared perforated sheet samples were formed upto onset of necking or initiation of fracture using a double action hydraulic press of capacity $2000 \mathrm{kN}$ with standard die and punch set up. A typical punch-die assembly used in the forming process is shown in Fig. 2. Because of the variation in the width of the samples, they were subjected to different states of strain namely Tension-Tension, Plane Strain and Tension-Compression during forming (Duan et al., 2006). During forming the perforated sheets deformed plastically. Before and after forming, the distances between two equivalent points along longitudinal (major) and transverse (minor) directions were measured in the necked region (Baik et al., 1995). The major true strain $\left(\varepsilon_{1}\right)$ and minor true strain $\left(\varepsilon_{2}\right)$ are then calculated using the formulae given in equation (1) and (2) respectively. FLD was drawn by the standard procedure said in the previous section. FLD (Narayanasamy and Sathiya, 2006) was drawn by plotting the minor strain in abscissa and corresponding major strain in ordinate and by drawing a smooth curve connecting these points.

$$
\begin{aligned}
& \text { Major true strain }\left(\varepsilon_{1}\right)=\ln \left[\frac{\text { Distance between two equivalent points after forming in the major axis }}{\text { Distance between two equivalent points before forming in the major axis }}\right] \\
& \text { Minor true strain }\left(\varepsilon_{2}\right)=\ln \left[\frac{\text { Distance between two equivalent points after forming in the minor axis }}{\text { Distance between two equivalent points before forming in the minor axis }}\right]
\end{aligned}
$$

\section{Results and discussions}

3.1 Microstructure and chemical composition: The chemical composition of the perforated Al 8011 sheet taken for study is given in Table 1. It contains a smaller percentage of Iron (Fe) and Silicon ( $\mathrm{Si}$ ), which increases the strength of Aluminium. In addition to this, it contains very little amount of manganese, which increases the corrosion resistance. The microstructures of the sheets taken for the study are shown in Fig. 3. The optical micrograph (Fig. 3(a)) shows large amount of inclusions present in the material. Meanwhile, the AA8011 alloy sheet has a large number of the second-phase particles, the size of which is smaller than $5 \mu \mathrm{m}$. In the $\mathrm{Al} 8011$ sheet, two kinds of particles can be observed (Fig. 5(b)) that is, some particles are gray and the others are white in the SEM micrographs. From several references in the literature it was confirmed that the white particles are Si precipitates, the gray ones are $\alpha-\mathrm{AlFeSi}(\mathrm{Al} 8 \mathrm{Fe} 2 \mathrm{Si}$ ) intermetallic compounds and the size of the $\alpha-\mathrm{AlFeSi}$ compounds is much larger than that of the $\mathrm{Si}$ particles.

3.2 Experimental results and data analysis: The plan of the experiment was developed for assessing the influence of the diameter of the circular perforation and ligament width on the major limiting true strain $(\varepsilon 1)$ and minor limiting true strain $(\varepsilon 2)$. The Table 4 illustrates the maximum value of the experimental results for $\varepsilon 1$ and $\varepsilon 2$ in three different conditions. Fig. 4 shows the forming limit diagrams of perforated $\mathrm{Al} 8011$ sheets which give the maximum limiting strains. 


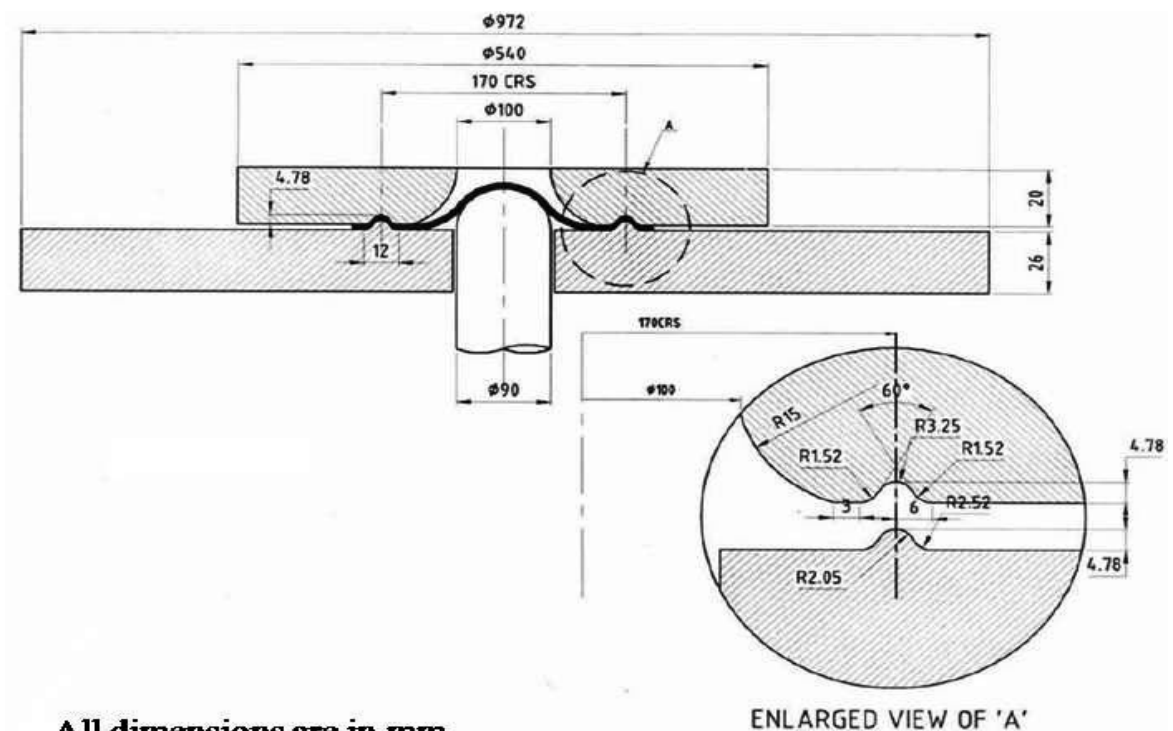

Figure 2. Punch Die assembly

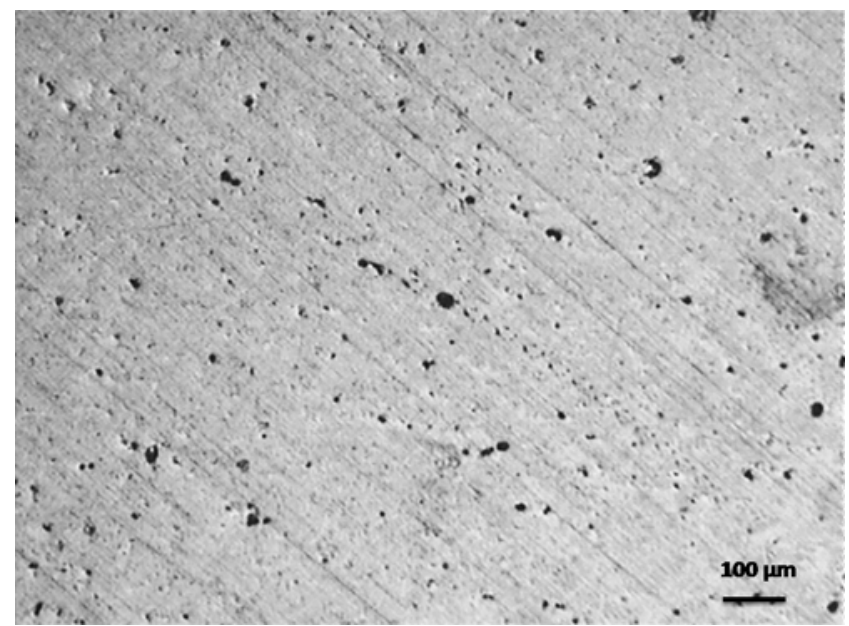

a) Optical micrograph of $2 \mathrm{~mm}$ thickness

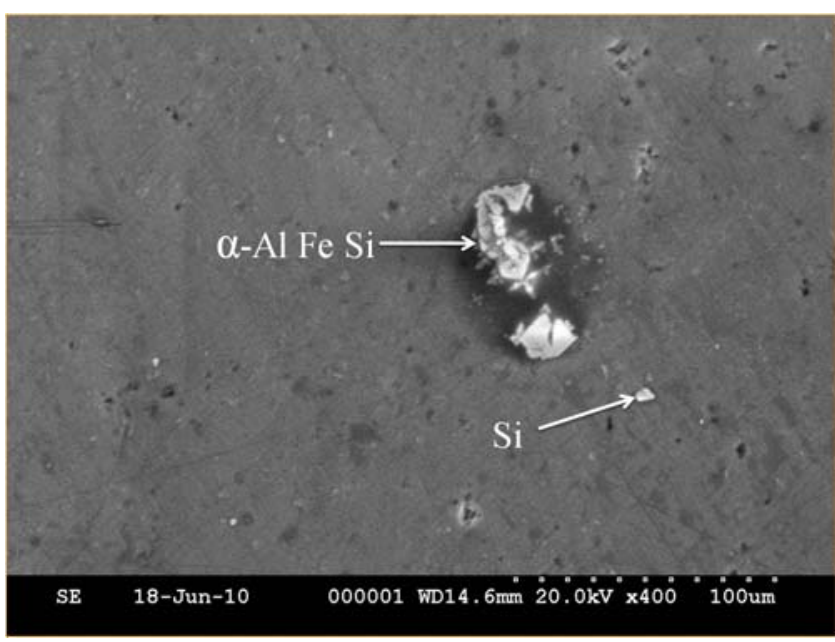

b) SEM micrograph of $2 \mathrm{~mm}$ thickness

Figure 3. Microstructure of $\mathrm{Al} 8011$

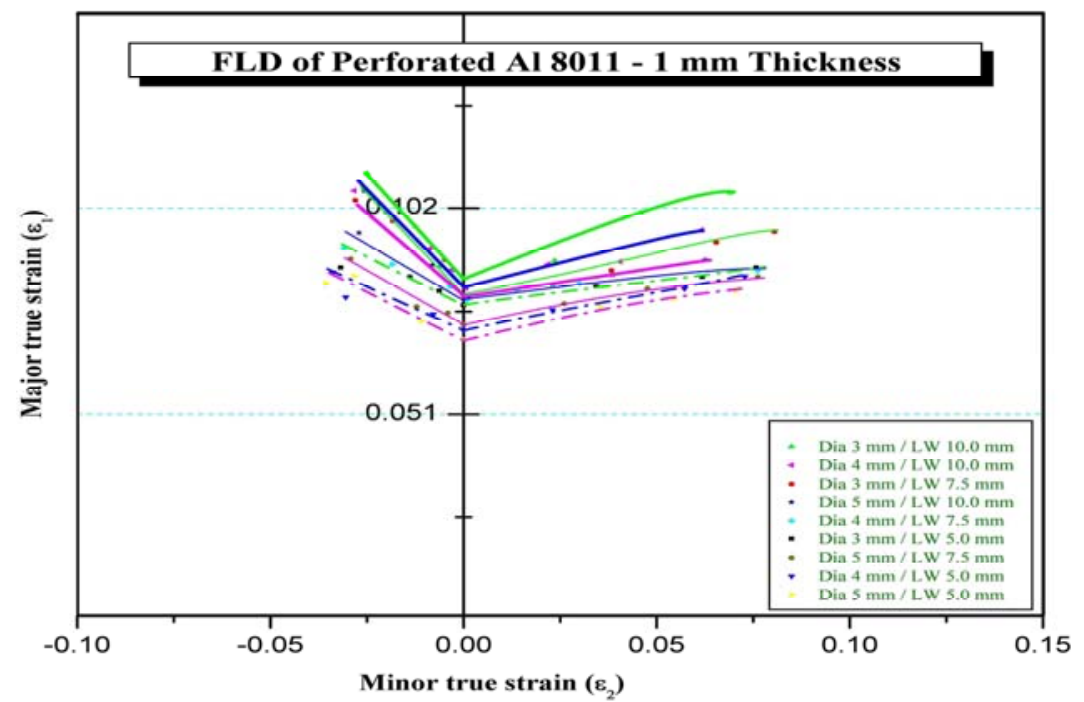

Figure 4. Forming limit diagrams of perforated Al 8011 sheets 
The analysis of variance (ANOVA) (Anastasiou, 2002) establishes the relative significance of factors in terms of their percentage contribution to the response. From equation (3) to (8) the total sum of squares, mean squares, variance and F-test value were determined.

$$
\begin{aligned}
& S_{m}=\frac{\left[\sum Y_{i}\right]^{2}}{9} \\
& S_{T}=\sum Y_{i}^{2}-S_{m} \\
& S_{A}=\frac{\left[\sum Y_{A i}\right]^{2}}{N}-S_{m} \\
& S_{E}=S_{T}-\sum S_{A} \\
& V_{A}=\frac{S_{A}}{f_{A}} \\
& F_{A 0}=\frac{V_{A}}{V_{E}}
\end{aligned}
$$

where, $S T$ is the sum of squares due to the total variation, $S_{m}$ is the sum of squares due to the mean, $S A$ is the sum of squares due to

\begin{tabular}{|c|c|c|c|c|c|c|c|}
\hline \multirow{2}{*}{ Test } & \multirow{2}{*}{$D(\mathrm{~mm})$} & \multirow{2}{*}{$W(\mathrm{~mm})$} & \multicolumn{2}{|c|}{ Tension-Compression strain condition } & \multirow{2}{*}{ Plane strain } & \multicolumn{2}{|c|}{ Tension-Tension $\quad$ strain condition } \\
\hline & & & major strain $\left(\varepsilon_{1}\right)$ & minor strain $\left(\varepsilon_{2}\right)$ & & major strain $\left(\varepsilon_{1}\right)$ & minor strain $\left(\varepsilon_{2}\right)$ \\
\hline 1 & 3 & 5 & 0.0873 & -0.0317 & 0.0781 & 0.0873 & 0.0758 \\
\hline 2 & 3 & 7.5 & 0.1039 & -0.0280 & 0.0805 & 0.096175606 & 0.0805 \\
\hline 3 & 3 & 10 & 0.1106 & -0.0249 & 0.0848 & 0.1057 & 0.0691 \\
\hline 4 & 4 & 5 & 0.0862 & -0.0339 & 0.0718 & 0.0852 & 0.0728 \\
\hline 5 & 4 & 7.5 & 0.0921 & -0.0309 & 0.0794 & 0.0866 & 0.0762 \\
\hline 6 & 4 & 10 & 0.1063 & -0.0283 & 0.0822 & 0.0966 & 0.0616 \\
\hline 7 & 5 & 5 & 0.0834 & -0.0356 & 0.0695 & 0.0816 & 0.0705 \\
\hline 8 & 5 & 7.5 & 0.0895 & -0.0292 & 0.0733 & 0.0821 & 0.0476 \\
\hline 9 & 5 & 10 & 0.1062 & -0.0257 & 0.0800 & 0.0892 & 0.0627 \\
\hline
\end{tabular}
parameter $A$ ( $A=$ Diameter of the perforation and Ligament width), $S E$ is the sum of squares due to error, $Y_{i}$ is the output value of each experiment $(\mathrm{i}=1,2, \ldots, 9), Y A_{i}$ is the sum of the $i$ level of parameter $A(i=1,2,3), N$ is the repeating number of each level of parameter $A, f A$ is the degree of freedom of parameter $A, V A$ is the variance of parameter $A$ and $F A_{0}$ is the $F$-test value of parameter A.

Table 4. Values of limiting major strain $\left(\varepsilon_{1}\right)$ and limiting minor strain $\left(\varepsilon_{2}\right)$ as a function of size of perforation and ligament width

3.3 Influence of the variables on limiting major strain and limiting minor strain in Tension - Compression condition: The plan of tests was developed with the aim of relating the influence of the diameter of the circular perforation and the ligament width of the perforation with the major and minor limiting strain. Table 5 shows the results of ANOVA associated with major and minor strains in tension-compression condition obtained from the $\mathrm{L}_{9}$ array based on Taguchi method. These analyses were carried out for a level of significance of $5 \%$, i.e. for a level of confidence of $95 \%$. The last column of the table shows the percentage of contribution (P) of each factor on the total variance. From the analysis of this table it can be observed that the diameter of the circular perforation 
$(P=24.78 / 21.98 \%)$ and the ligament width of the perforation $(P=70.04 / 72.55 \%)$ have statistical and physical significance on the major and minor strains in tension - compression condition. Because Test $F>\mathrm{F} \alpha=5 \%$ and the $\mathrm{P}(\%)>$ error. The evolution of the major and minor strain in function of the ligament width, for several diameters of circular perforations, can be seen in Fig. 5 and Fig. 6. It can be evidenced the values of major and minor strain increases with ligament width and decreases with diameter.

Table 5. Analysis of variance (ANOVA) and F test for limiting major strain and limiting minor strain in Tension - Compression condition

\begin{tabular}{|l|c|c|c|c|c|c|}
\hline $\begin{array}{c}\text { Source of } \\
\text { variance }\end{array}$ & Sum of square & $\begin{array}{c}\text { Degrees of } \\
\text { freedom }\end{array}$ & Variance & Test $F$ & $\begin{array}{c}F_{\alpha}= \\
5 \%\end{array}$ & $\begin{array}{c}\text { Percentage of } \\
\text { contribution (\%) }\end{array}$ \\
\hline major strain $\left(\varepsilon_{1}\right)$ & \\
\hline$D(\mathrm{~mm})$ & $9.40 \mathrm{E}-05$ & 2 & $4.70 \mathrm{E}-05$ & 4.177 & 6.94 & 24.78 \\
\hline$W(\mathrm{~mm})$ & 0.00073 & 2 & 0.00036 & 32.550 & 6.94 & 70.04 \\
\hline Error & $4.509 \mathrm{E}-05$ & 4 & $1.12 \mathrm{E}-05$ & - & - & 5.16 \\
\hline Total & 0.00087 & 8 & - & - & - & 100 \\
\hline minor strain $\left(\varepsilon_{2}\right)$ & \\
\hline$D(\mathrm{~mm})$ & $1.23 \mathrm{E}-05$ & 2 & $6.15 \mathrm{E}-06$ & 4.392 & 6.94 & 21.98 \\
\hline$W(\mathrm{~mm})$ & $8.47 \mathrm{E}-05$ & 2 & $4.23 \mathrm{E}-05$ & 30.255 & 6.94 & 72.55 \\
\hline Error & $5.60 \mathrm{E}-06$ & 4 & $1.40 \mathrm{E}-06$ & - & - & 5.45 \\
\hline Total & 0.00010 & 8 & - & - & - & 100 \\
\hline
\end{tabular}

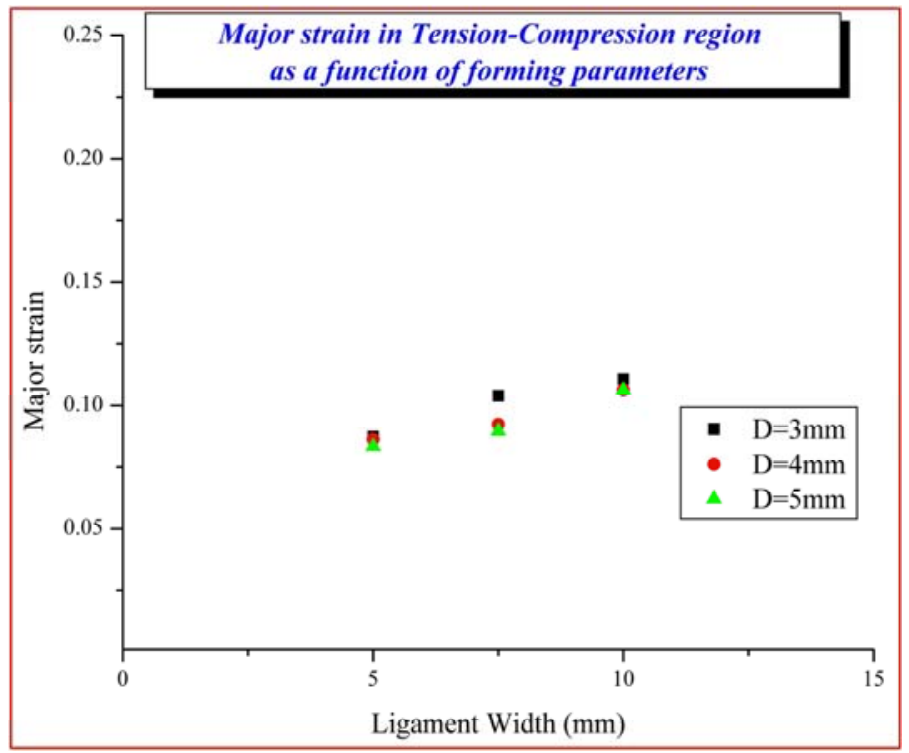

Figure 5. Limiting Major strain in Tension - Compression condition as a function of variables

3.4 Influence of the variables on limiting major strain in plane strain condition: Table 6 shows the results of ANOVA associated with obtained from the $\mathrm{L}_{9}$ array based on Taguchi method. From the analysis of this table it can be observed that the diameter of the circular perforation $(P=28.28 \%)$ and the ligament width of the perforation $(\mathrm{P}=69.65 \%)$ have statistical and physical significance on the plane strain. Because Test $F>F_{\alpha}=5 \%$ and the $P(\%)>$ error. The evolution of the plane strain in function of the ligament width, for several diameters of circular perforations, can be seen in Fig. 7. It can be evidenced the values of major and minor strain increases with ligament width and decreases with diameter.

3.5 Influence of the variables on limiting major strain and limiting minor strain in Tension - Tension condition: Table 7 shows the results of ANOVA associated with major and minor strains in tension-tension condition obtained from the $\mathrm{L}_{9}$ array based on Taguchi method. From the analysis of this table it can be observed that the diameter of the circular perforation $(\mathrm{P}=40.60 /$ $26.20 \%)$ and the ligament width of the perforation $(P=51.49 / 71.84 \%)$ have statistical and physical significance on the major and minor strains in tension - compression condition. Because Test $F>F_{\alpha}=5 \%$ and the $\mathrm{P}(\%)>$ error. The evolution of the major and minor strain in function of the ligament width, for several diameters of circular perforations, can be seen in Fig. 8 and Fig. 9. It can 
be evidenced the values of major and minor strain increases with ligament width and decreases with diameter. The percentage of contribution for each factor on major and minor strain can be seen in Fig.10. It can be evidence that the major and minor strain is more influenced by the ligament width than the diameter.

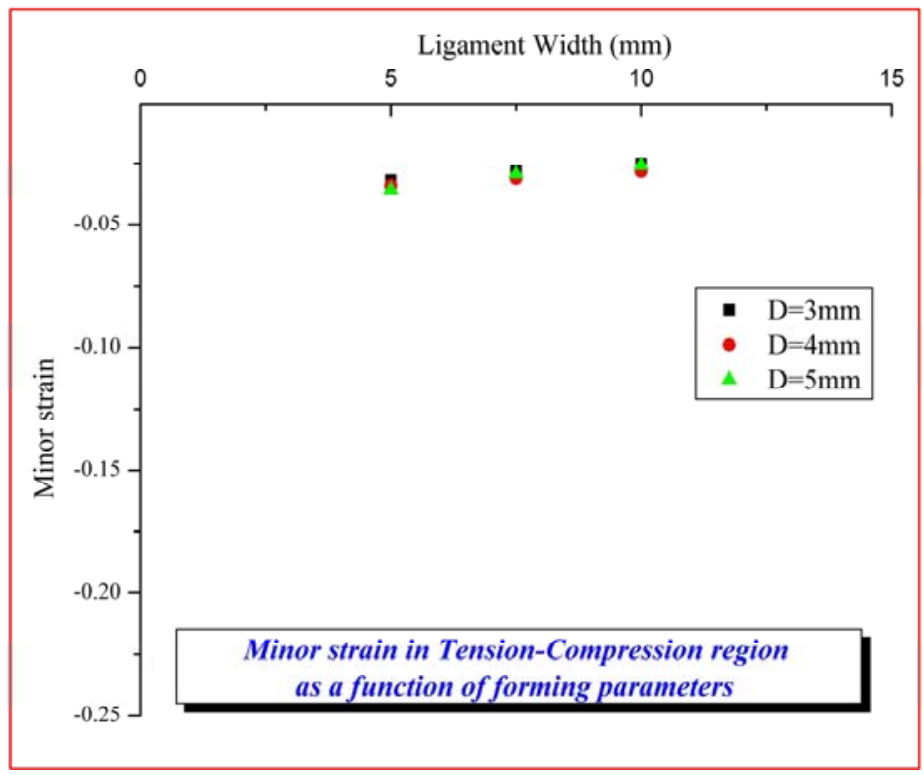

Figure 6. Limiting Minor strain in Tension - Compression condition as a function of variables

Table 6. Analysis of variance (ANOVA) and F test for major strain in plane strain condition

\begin{tabular}{|c|c|c|c|c|c|c|}
\hline $\begin{array}{c}\text { Source of } \\
\text { variance }\end{array}$ & $\begin{array}{c}\text { Sum of } \\
\text { square }\end{array}$ & $\begin{array}{c}\text { Degrees of } \\
\text { freedom }\end{array}$ & Variance & Test $F$ & $\begin{array}{c}F_{\alpha}= \\
5 \%\end{array}$ & $\begin{array}{c}\text { Percentage of } \\
\text { contribution (\%) }\end{array}$ \\
\hline$D(\mathrm{~mm})$ & $2.79 \mathrm{E}-05$ & 2 & $1.39 \mathrm{E}-05$ & 27.426 & 6.94 & 28.28 \\
\hline$W(\mathrm{~mm})$ & $6.87 \mathrm{E}-05$ & 2 & $3.43 \mathrm{E}-05$ & 67.531 & 6.94 & 69.65 \\
\hline Error & $2.03 \mathrm{E}-06$ & 4 & $5.09 \mathrm{E}-07$ & - & - & 2.06 \\
\hline Total & $9.87 \mathrm{E}-05$ & 8 & - & - & - & 100 \\
\hline
\end{tabular}

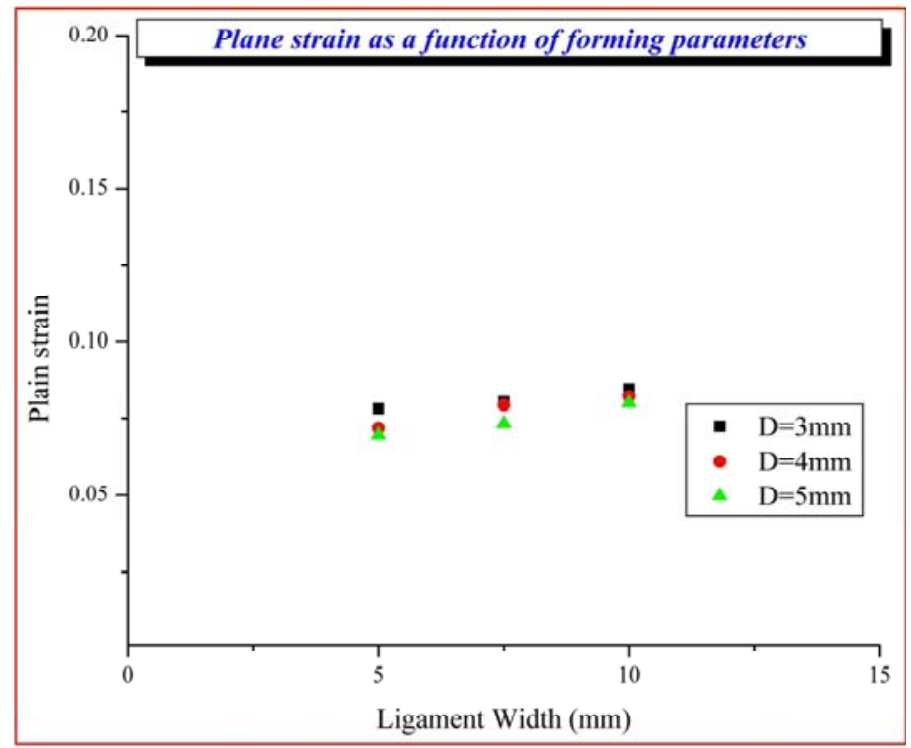

Figure 7. Limiting major strain in Plane strain condition as a function of variables 
Table 7. Analysis of variance (ANOVA) and $F$ test for limiting major strain and limiting minor strain in Tension - Tension condition

\begin{tabular}{|c|c|c|c|c|c|c|}
\hline $\begin{array}{c}\text { Source of } \\
\text { variance }\end{array}$ & $\begin{array}{c}\text { Sum of } \\
\text { square }\end{array}$ & $\begin{array}{c}\text { Degrees of } \\
\text { freedom }\end{array}$ & Variance & Test F & $\begin{array}{c}F_{\alpha}= \\
5 \%\end{array}$ & $\begin{array}{c}\text { Percentage of } \\
\text { contribution }(\%)\end{array}$ \\
\hline \multicolumn{7}{|c|}{ major strain $\left(\varepsilon_{1}\right)$} \\
\hline $\mathrm{D}(\mathrm{mm})$ & 0.000189 & 2 & $9.47 \mathrm{E}-05$ & 10.290 & 6.94 & 40.60 \\
\hline $\mathrm{W}(\mathrm{mm})$ & 0.00024 & 2 & 0.00012 & 13.049 & 6.94 & 51.49 \\
\hline Error & $3.68 \mathrm{E}-05$ & 4 & $9.20 \mathrm{E}-06$ & - & - & 7.89 \\
\hline Total & 0.00046 & 8 & - & - & - & 100 \\
\hline \multicolumn{7}{|c|}{ minor strain $\left(\varepsilon_{2}\right)$} \\
\hline $\mathrm{D}(\mathrm{mm})$ & $5.29 \mathrm{E}-05$ & 2 & $2.64 \mathrm{E}-05$ & 16.578 & 6.94 & 26.20 \\
\hline $\mathrm{W}(\mathrm{mm})$ & 0.00026 & 2 & 0.000133 & 83.751 & 6.94 & 71.84 \\
\hline Error & $6.38 \mathrm{E}-06$ & 4 & $1.59 \mathrm{E}-06$ & - & - & 1.95 \\
\hline Total & 0.00032 & 8 & - & - & - & 100 \\
\hline
\end{tabular}

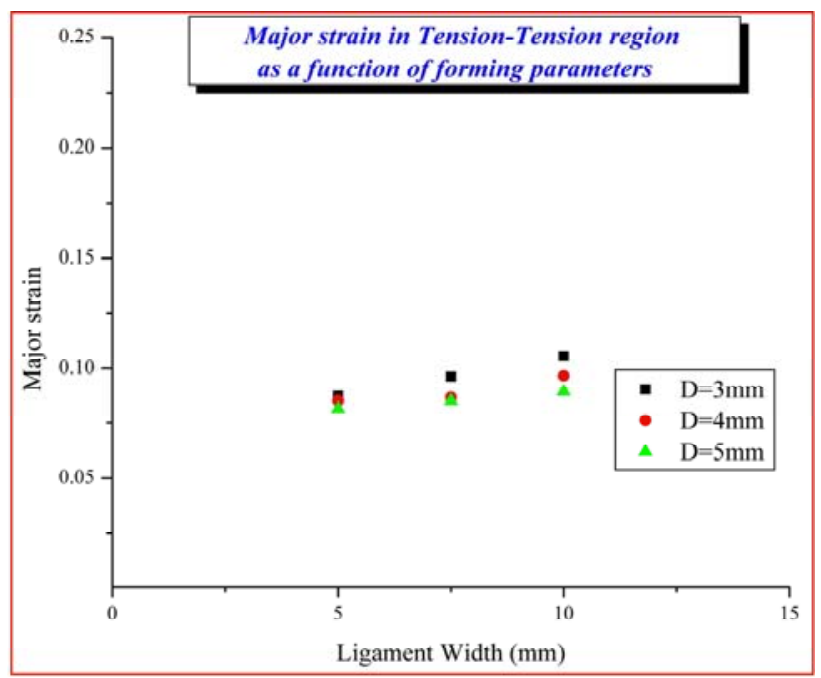

Figure 8. Limiting Major strain in Tension - Tension region as a function of variables

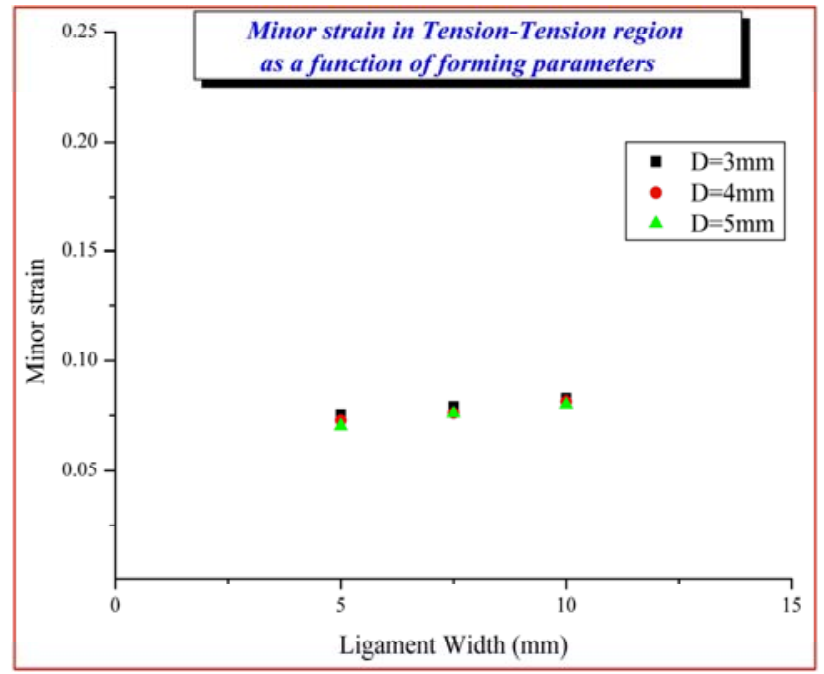

Figure 9. Limiting Minor strain in Tension-Tension region as a function of variables 


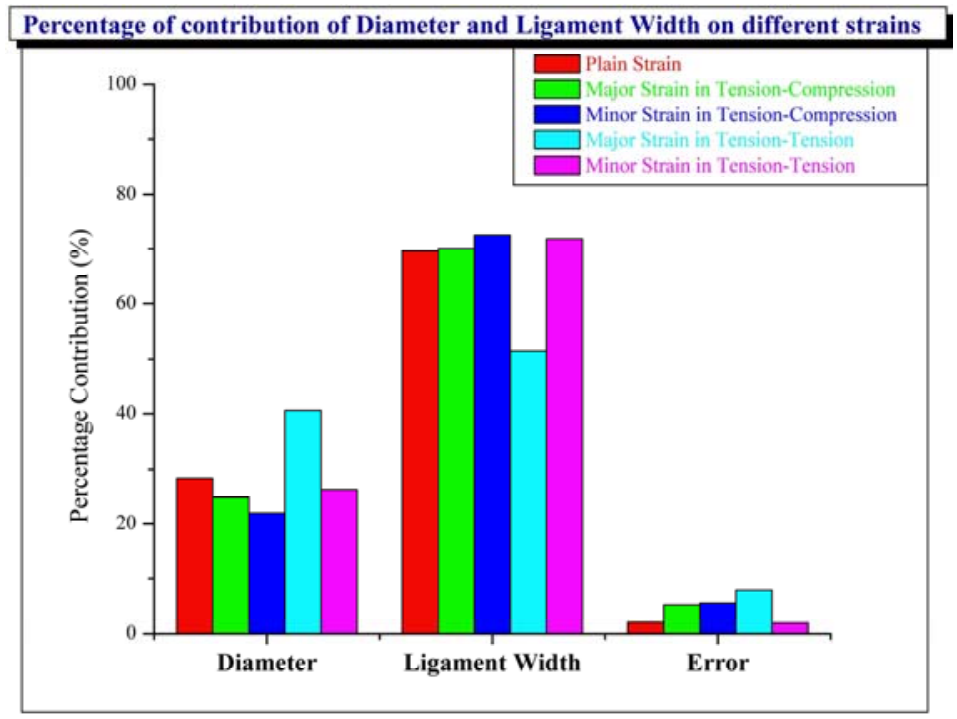

Figure 10. Percentage of contribution of size of perforation and ligament width on strains in different region

\section{Conclusions}

This investigation attains an understanding of the variables of perforated sheets. According to the experimental results and statistical analysis of ANOVA, the following conclusions have been drawn.

o From experimental FLD it is evident that the forming limit strains are increased with the ligament width and decreased with diameter of the perforations. To suggest larger implications now that the evidence has been presented

0 Among the combinations of size of perforation and ligament width the $3 \mathrm{~mm}$ diameter circular perforation with $10 \mathrm{~mm}$ ligament width have higher formability and the $5 \mathrm{~mm}$ diameter circular perforation with $5 \mathrm{~mm}$ ligament width have lower formability.

0 Both the size of perforation and the ligament width of the perforated sheet have the physical and statistical influence on the limiting major strain and limiting minor strain in all the three strain conditions.

0 Among the variables the ligament width has the highest physical and statistical influence on the limiting major strain and limiting minor strain in all the three strain conditions.

This work can be extended for various thicknesses of the sheets of the same material and can compare the influences of the thickness with the diameter of perforations and ligament widths on forming limit strains.

\section{References}

Anastasiou K.S., 2002. Optimization of the aluminium die casting process based on the Taguchi method. J Eng Manuf, Vol.216, No. 7, pp. 969-977.

Baik S.C., Han H.N., Lee S.H., Oh K.H., Lee D.N., 1997. Plastic behaviour of perforated sheets under biaxial stress state, International Journal of Mechanical Sciences, Vol. 39, No. 7, pp. 781-793.

Baik S.C., Han H.N., Lee S.H., Oh K.H., Lee D.N., 2000. Plastic behaviour of perforated sheets with slot-type holes under biaxial stress state, Int. J. Mech. Sci. Vol. 42, No. 3, pp. $523-536$.

Baik S.C., Oh K.H., Lee D.N., 1995. Forming limit diagram of perforated sheet, Scr. Metall. Mater. Vol. 33, No.8, pp. 1201-1207.

Chen F.K., 1993. Analysis of plastic deformation for sheet metals with circular perforations, J. Mater. Process. Technol., Vol.37 pp. $175-188$.

Duan X., Jain M., and Wilkinson D.S., 2006. Development of a heterogeneous microstructurally based finite element model for the prediction of forming limit diagram for sheet material, Metallurgical and Materials Transactions A, Vol. 37, pp. 3489.

Goodwin G.M., 1968. Application of strain analysis to sheet metal forming problems in the press shop, Metall. Italiana, Vol.60, pp. 764-74.

http://www.perforatedsheet.net/perforatedsheet/uses.html

Keeler S.P., 1965. Determination of forming limits in automotive stampings, Sheet Met Ind, Vol. 42, pp. 683-91.

Ko D, Kim D, Kim B, 1999. Application of artificial neural network and Taguchi method to preform design in metal forming considering workability. Int J Mach Tool Manuf, Vol. 39, pp. 771-785.

Lee Y.C., Chen F.K., 2000. Yield criterion for a perforated sheet with a uniform triangular pattern of round holes and a low ligament ratio, J. Mater. Process. Technol. Vol.103, pp. 353-361. 
Li B., Nye T.J, Metzger D.R., 2006. Multi-objective optimization of forming parameters for tube hydroforming process based on the Taguchi method, Int J Adv Manuf Technol, Vl. 28, pp. 23-30.

Mahapatra S.S. and Chaturvedi V., 2009, Modelling and analysis of abrasive wear performance of composites using Taguchi approach, International Journal of Engineering, Science and Technology, Vol. 1, No. 1, pp. 123-135.

Mary-Anne Kulas, Paul E. Krajewski, John R. Bradley, and Eric M. Taleff, 2007. Forming-limit diagrams for hot-forming of AA5083 aluminum sheet: continuously cast material, Journal of Materials Engineering and Performance, Vol.16, No. 3, pp. 308.

Mathivanan D., Nouby M. and Vidhya R., 2010, Minimization of sink mark defects in injection molding process - Taguchi approach, International Journal of Engineering, Science and Technology, Vol. 2, No. 2, 2010, pp. 13-22.

Montgomery DC, 1997. Design and analysis of experiments, 4th ed, John Wiley \& Sons, New York.

Moshat S., Datta S., Bandyopadhyay A. and Pal P.K., 2010, Optimization of CNC end milling process parameters using PCAbased Taguchi method, International Journal of Engineering, Science and Technology, Vol. 2, No. 1, pp. 92-102

Moshat S., Datta S., Bandyopadhyay A. and Pal P.K., 2010, Parametric optimization of CNC end milling using entropy measurement technique combined with grey-Taguchi method, International Journal of Engineering, Science and Technology, Vol. 2, No. 2, 2010, pp. 1-12.

Narayanasamy R., Parthasarathi N. L., Ravindran R., Sathiya Narayanan C., 2008. Analysis of fracture limit curves and void coalescence in high strength interstitial free steel sheets formed under different stress conditions, J Mater Sci, Vol 43, pp. 33513363.

Narayanasamy R., Sathiya N.C., 2006. Forming limit diagram for Indian interstitial free steels, Materials and Design, Vol.27, pp. 882-899.

Ross P., 1988. Taguchi techniques for quality engineering - Loss function, Orthogonal experiments, Parameter and Tolerance design, McGraw-Hill, New York, pp 10-15.

Ross PJ, 1988. Taguchi techniques for quality engineering, New York, McGraw-Hill.

Taguchi G, 1990. Introduction to quality engineering, Tokyo, Asian productivity organization.

Taguchi G., 1993. Taguchi on robust technology development methods, ASME, New York, pp. 1-40.

Taguchi G., Konishi S., 1987. Taguchi methods, Orthogonal arrays and linear graphs, Tool for quality engineering, American Supplier Institute, pp. 35-38.

\section{Biographical notes}

K. Elangovan is a research scholar in the Department of Production Engineering, National Institute of Technology, Tiruchirappalli, India and received M. Tech. from National Institute of Technology, Tiruchirappalli, India in 2004 and received B.E. from Government College of Engineering, Salem, India in 1999. He has published 2 papers in International Journals. He has published 2 papers in the proceedings of the international conferences. His research interests include sheet metal forming.

Dr. C. Sathiya Narayanan is an Assistant Professor in the Department of Production Engineering, National Institute of Technology, Tiruchirappalli, India. He has more than 15 years of experience in teaching and research. His current area of research includes Sheet metal forming and Electro Discharge Machining. He has published more than thirty papers in referred international journals. He has also presented more ten research articles in national and international conferences.

Received July 2010

Accepted August 2010

Final acceptance in revised form August 2010 